\title{
An architectural love of the living: bio-inspired design in the pursuit of ecological regeneration and psychological wellbeing
}

\author{
M. Pedersen Zari \\ School of Architecture, Victoria University, Wellington, New Zealand
}

\begin{abstract}
A growing amount of architectural discourse explores analogies between ecosystems and living organisms, and architectural design that increases the capacity for regeneration. This is referred to here as bio-inspired design. This paper examines the relationship between biophilic and biomimetic approaches to architectural design as two aspects of bio-inspired design.

The theory that bio-inspired design is inherently linked in the creation of regenerative architecture, able to increase capacity for self repair in both living ecosystems and the human psyche, is examined. Intersections, or mutualisms, between design to improve the wellbeing of ecosystems and design to improve human wellbeing, such as biomimicry and biophilia, are analysed and may illustrate the key aspects of bio-inspired design that could contribute to regenerative design. The implications of such an approach are discussed, and the scientific basis of such a process is investigated.
\end{abstract}

Keywords: biophilia, biomimicry, ecosystem, wellbeing, architecture, regeneration, restoration, sustainability.

\section{Introduction}

The definition of cutting edge sustainable architecture is changing rapidly [1]. Aiming for 'neutral' or 'zero' environmental impact buildings in terms of energy, carbon, waste or water are worthwhile targets. It is becoming clear, however, that buildings will need to go beyond having little negative environmental impact in the future, to having net positive environmental benefits [2]. Reed describes the transition from conventional practice and green architecture (negative environmental impact), to sustainable architecture (zero 
impact), through to design with positive environmental impact. Restorative architecture is the human assisted healing of natural systems, while reconciliatory design is the integration of humans with ecosystems. Regenerative architecture is the participation of humans as part of the living system, for the mutual benefit of both [3].

Aspects of restorative, reconciliatory and regenerative architecture are beginning to emerge in the built environment, but translation into comprehensive examples of architecture has not been rapid to this point. In the absence of tangible regenerative design concepts, the intersections in bio-inspired design, which seeks to improve both the ecological and psychological suitability of the built environment, could be a crucial component of creating comprehensive regenerative architecture. As Reed points out, 'regeneration of the health of the humans and local earth systems is an interactive process - each supports the other in a mutually beneficial way. This awareness or consciousness of vital and viable interrelationship is the beginning of a whole system healing process.' [3].

The need to include human psychology design methodologies to affect environmental restoration and conservation is demonstrated by Walsh [4]: '...All the major global threats to human survival and wellbeing are now primarily human caused. That is, they stem directly from our own behaviour and can therefore largely be traced to psychological origins.'

\section{Regenerative architecture strategies}

Regenerative design is described as 'building capacity not things' [3]. Buildings are designed as systems that interact in complex ways with each other, the living world, and their human inhabitants rather than as objects. Regenerative architecture would include people as part of ecosystems, and address the human relationship to the living world, in terms of personal and collective physical and psychological health $[3,5]$. This implies that buildings would need to produce more than they need, and would be able to transform and filter waste into health giving resources. It a departure from the idea that the best buildings can be is 'neutral' in relation to the living world.

Leading thinkers on regenerative design such as William Reed and Ray Cole argue that a shift from a built environment that ultimately is degenerating ecosystems to one which restores local environments and regenerates capacity for ecosystems to thrive, will not be a gradual process of improvements but will in fact require a fundamental rethinking of architectural design [3]. Biomimetic and biophilic architecture, as components of bio-inspired design may offer some insights into exactly how that could happen.

\section{Ecosystems and the human psyche: biophilic architecture}

The term biophilia means 'the tendency to focus on life, and life-like processes' [6]. Biophilic design seeks to incorporate an understanding of the process and importance of the human psychological connection with the perceivable living world. It combines evidence and theories from the areas of environmental 
psychology, evolutionary psychology, ecological psychology, neuroscience, and from those researchers and designers investigating the biophilia hypothesis and its implications for humans and for design [7].

Much of the evidence that biophilic design draws on comes from the premise that because the human mind evolved in the natural world, survival behaviours and responses related to certain organisms, landscapes and natural forms are genetically inherited, and affect the human sense of belonging and wellbeing. Evidence suggests for example, that people feel less stressed, are able to concentrate better and are even able to physically and psychologically heal more rapidly, when they have a connection with the living world [7-10].

Several researchers provide lists of elements of biophilic design along with explanations of their scientific basis [11-13]. The two most common manifestations of biophilic design are firstly, that elements of the living world, particularly plants should be brought into urban landscapes and building interiors [14]. An example of this approach is seen in the Genzyme Headquarters in Massachusetts, designed by Behnisch and Behnisch in 2004 [13]. Extensive use of gardens, running water, and natural light and materials are employed.

The second interpretation is that to increase psychological wellbeing, the built environment should mimic the geometry or morphology of natural form. One example of this is the investigation into the psychological benefits of fractal architecture, where similar forms repeat themselves at varying scales $[15,16]$. Gothic and Hindu architecture is a commonly cited example of fractal architecture. Another early example is René Binet's entrance to the 1900 Paris World Exposition, based on Ernst Haeckel's fractal drawing of a radiolarian [17]. Frank Lloyd Wright's Palmer House in Michigan (1950) also exemplifies the concept with its fractal floor plan, where the triangle is repeated in several different scales. Steven Holl's Simmons Hall (2002) which mimics the openings in a sea sponge is also likened to fractal design [15].

The architectural innovation of biophilic design is its potential contribution to creating a built environment that humans can thrive in both physically and psychologically.

\section{Ecosystems and the built environment: biomimetic architecture}

Biomimicry is the emulation of strategies seen in biology as a basis for design. It is the mimicry of the forms, materials, construction methods, processes, or functions, of an organism, an organism behaviour, or an entire ecosystem [18].

An example of biomimetic architecture is Grimshaw Architects' proposal for a theatre called Teatro del Agua in the Canary Islands. The theatre is also a unique desalination plant based on how the Namibian desert beetle and the hydrological cycle work. The beetle lives in a desert with little rainfall but is able to capture moisture from the swift fog that moves over it by tilting its body into the wind. Droplets form on the surface of the beetle's back because the surface of its shell is cooler than the surrounding air, and so the water condenses. The droplets then roll down into its mouth [19]. The hydrological cycle is based of 
course on evaporation and precipitation. In the building, seawater will be passed over a series of evaporative grills. As the sea breeze moves through them some of the water evaporates, leaving salt behind. The moist air then continues until it hits pipes holding cool seawater. As the warm moist air touches the cool pipes, condensation forms and fresh water trickles down to be collected for use. Excess water and cooling can be transferred to neighbouring gardens and buildings. This proposal demonstrates some of the potential biomimicry has in creating architecture that goes beyond just increasing efficiencies, to one that creates resources.

Mimicking an organism alone however, without also mimicking how it is able to participate in and contribute to the larger context of the ecosystem it is in, may result in designs that are conventional or below average in terms of environmental impact [20]. The greatest potential of biomimicry to form the basis of a regenerative built environment may therefore lie in mimicking ecosystems [21].

Ecosystems are resilient, resourceful and opportunistic. They adapt and evolve, have the capacity to heal, and importantly, they create conditions conducive to ongoing life $[18,22]$. If the living world is to give designers insights into architectural design, buildings may be considered as parts of a living system. In the same way as an ecosystem, such buildings could be designed to: produce energy and nutrients (materials); clean air and water; and use and transform waste in a complex, adaptive, and cyclic system. Several authors have compiled general principles for ecosystem-based biomimicry [18, 23], and other methods, including constructional theory for incorporating understanding of ecosystems into architectural design [20, 22, 24-28]. It is these ecosystem-based biomimetic ideas that are examined for their relevance to regenerative architecture

\section{Mutualisms: the symbiosis of biomimicry and biophilia}

A mutualism is described in biological terms as 'a relationship between two species of organisms in which both benefit from the association'. In social terms, a mutualism describes the interdependence of social elements that is beneficial to both the individual and society (Definitions taken from Dictionary.com. Date accessed $14^{\text {th }}$ February 2008. http://dictionary.reference.com/). Mutualisms between design to improve the wellbeing of ecosystems and design to improve human wellbeing, such as biomimicry and biophilia, may illustrate the key aspects of bio-inspired design that could contribute to regenerative design. These mutualisms are intended to complement 'aspects of a regenerative approach to design' outlined by Reed [3], and are offered as a starting point for the conceptual development of regenerative design. Through a literature review and an analysis of biophilic and biomimetic architectural design, eight such mutualisms have been identified:

\subsection{Mutualism one: leverage and understanding relationships}

Both biomimicry and biophilia seek to understand the living world and the human relationship to it. Biomimicry utilises the translation of biological or 
ecological strategies to improve the sustainability of the architecture. The rethinking of the physical relationship between human built form and the rest of the living world is central to a holistic form of biomimicry [20]. Relationships between buildings and building systems are also examined [18].

Biophilic design also leverages and understanding of relationships to create built form that can positively affect the relationship of humans to the built environment, and more broadly the psychological relationship of humans to the living world [29].

This demonstrates that understanding, harnessing and creating relationships and therefore systems, rather than just applying technological solutions without an understanding of wider context, could be a crucial part of regenerative design [3].

\subsection{Mutualism two: base design on physical reality rather than theory alone}

A common aspect of both biomimicry and biophilia is that design decisions are based on an understanding of the physical world that is the human context. Biomimicry looks to understand and then mimic how organisms or ecosystems actually work. Biophilic design incorporates observed and tested human psychological responses to the living world.

Salingaros and Masden point out that modern building and urban design tends to ignore or contradict the physical living processes of the world. They suggest that it is the spilt between design based on a response to physical context, and design based on human derived meaning alone, such as temporary fashion styles, that has created 'inhumane' cities and buildings that do not increase human wellbeing and in fact may decrease it [14].

An application of this mutualism suggests that regenerative architecture should be based on a comprehensive understanding of the physical reality of the ecological and cultural context of the design.

\subsection{Mutualism three: avoid stylistic conformities}

Bio-inspired design is not a style in the same way that modernism or postmodernism are for example. Ecosystem-based biomimicry is concerned with replicating functions and processes that are independent of a certain aesthetic. Biophilic architecture too is not easily recognisable as a distinct aesthetic style, because the underlying concepts are interpreted in different ways by designers.

Regenerative architecture is also unlikely to adhere to a certain visual style, because it will be systems based and place specific. Just as with bio-inspired design, architecture will be deemed 'regenerative', not because of how it looks, but because of how it increases capacity for positive relationships between humans, their built environment and the rest of the living world.

\subsection{Mutualism four: the local is vital}

Ecosystem-based biomimicry and biophilic design both emphasise place based design. One of the principles of ecosystem-based biomimicry is that, the immediate or local context an organism lives in, generally provides the resources 
and information it needs [23]. Understanding and utilising the local context then becomes an important aspect of ecosystem-based biomimicry [18].

Biophilic design emphasises that meaningful connections to the local context, both culturally and ecologically, increase human well being [13]. It has been suggested that some great buildings of the past, are loved because the architect was more engaged with immediate context and could therefore translate the 'intrinsic qualities to enable... a strong connection' into built form [14].

Regenerative design should therefore ultimately be based on the design team having a deep and intimate understanding of the design context. Reed points out that we can best engage in restoration of those places where we live and therefore know well. Kellert sums this up in a different way: 'When this relationship among culture, environment, and architecture is pronounced, these places become alive for us, a part of our collective consciousness and identity' [13].

\subsection{Mutualism five: design to allow complexity}

Biomimicry and biophilia both resist the simplification of systems and form. Ecosystem-based biomimicry may use an understanding of the importance of complexity in the natural world to create multifunctional, robust, self organising systems, where emergent effects are possible [18].

Research into biophilia discusses increasing complexity of form, particularly fractal patterns as being attractive to humans, because they mimic human cerebral organisation [14]. Enhanced wellbeing has also been linked to the complexity and variability of a constantly changing natural environment through time [30-32]. 'Human beings connect physiologically and psychologically to structures embodying organised complexity more strongly than to environments that are either too plain, or which present disorganised complexity' [14].

The lesson from this mutualism is that regenerative design may seek to embrace complexity and leverage it to create positive feedbacks or selfreinforcing effects, both ecologically and psychologically.

\subsection{Mutualism six: translation and abstraction}

Because of the unique needs, resources and scales that humans work with, biomimicry necessarily involves an interpretation or adaptation from biology into a human context $[33,34]$. Biomimicry is not intended to a slavish exact copying of organisms, but instead an emulation of the strategies that organisms use to function.

This process of translation often results in designs that are not immediately similar to the organism that inspired them in terms of form, but utilise the same functional concepts. When environmental sustainability is the goal of design, mimicking form becomes less relevant. For example, a building that looks like an organism, but is made and functions in a conventional (rather than 'green') way is unlikely to be an environmentally sustainable building. A building that is able to mimic natural processes and can function like an ecosystem in its creation, use and eventual end of life has greater potential to contribute to a regenerative built environment. 
The superficial copying of form is also discussed by advocates of biophilic design as a shallow interpretation of bio-inspired design. 'There is a danger in... copying shapes that are irrelevant to a particular building or city... Making a giant copy of an organism... fails to provide any level of connectivity... [This] belies a fundamental misconception about living structure, which connects on the human levels of scale through organised details and hierarchal connections' [14]. Furthermore, it has been suggested incorporating translations, rather than exact copies, of natural form into architecture is a more comprehensive form of biophilic design. This is because it may not be living biological forms in themselves that nourish humans psychologically, but rather the underlying geometric or morphological complexity of living structure [14, 16, 35].

This mutualism suggests that regenerative architecture will avoid the shallow copying of form and processes and will make use of translation and abstraction to make designs relevant to particular contexts.

\subsection{Mutualism seven: use multidisciplinary knowledge}

Biomimetic and biophilic design both draw on knowledge from diverse fields of study. Biomimicry requires collaboration between biologists or ecologists, and designers. Biophilic design similarly requires a multidisciplinary team consisting of psychologists, neuroscientists, and designers. The multidisciplinary nature of bio-inspired design fits with the notion of an integrated and participatory design process being important to design for sustainability and social responsibility [36].

Regenerative design will likely have to be multidisciplinary and participatory in nature to take the myriad various aspects of human knowledge into account [3]. Bringing these together will be important in creating a comprehensive and widely relevant regenerative architecture.

\subsection{Mutualism eight: conserve, restore, and regenerate ecosystems}

The recognition of the fundamental importance of the health of ecosystems and the regeneration of them for the wellbeing of people is important in biomimicry. Living organisms and the systems they create are the source of design innovation. To lose more biodiversity is to lose potential design solutions. The aspect of respect for the living world, without romanticising nature is emphasised in much biomimicry literature [23, 33]. Benyus states for example: '...The companies, organizations and individuals who are learning from the natural world [could] donate a percentage of the royalties from every product and process to preserving the habitat of the organism that inspired the innovation' [36].

Wilson outlines the basis for a conservation ethic as it relates to biophilia [29]. He argues that there is an innate psychological need for humans to be in a positive relationship with other life forms, and that there is substantial evidence to make such a claim. Living forms and their geometric characteristics must be preserved because of the 'neurological nourishment' they provide [6]. This is echoed by Heerwagen and Orians, who state that 'a biologically impoverished 
planet will not only reduce humanity's economic options, it will diminish our emotional lives as well' [29].

Acknowledging and celebrating an increased respect for and care of the living world may therefore be a crucial part of regenerative architecture, and in fact may be reinforcing of both environmental and psychological wellbeing. Kellert states for example that 'communities with higher environmental quality [have] more positive environmental values and a higher quality of life, whereas those with lower environmental quality [tend] to reveal less environmental interest and [have] a lower quality of life' [14].

\section{Conclusion}

Addressing the current state of the built environment and ensuring new buildings are designed to the highest standard, is becoming increasingly urgent as the negative environmental impact of humans is understood, and our complete dependence on ecosystems is more apparent [37]. Sustainability in architecture is generally thought of in terms of resource efficiency, pollution reduction and mitigating impact on natural ecosystems. It can be argued however that human wellbeing and planetary wellbeing are intricately interwoven [37]. Such an understanding forms the basis for a regenerative approach to design.

As the depth and breadth of human knowledge is more readily available, and cross-disciplinary communication is possible, the boundaries of traditional areas of research are starting to merge. An understanding of ecology and psychology in architectural design, as demonstrated by biomimicry and biophilic design may signal significant ways forward for improving the built environment, particularly as a shift from goals of sustainable architecture to ones of regenerative architecture is made. This could transform ideas about what the built environment is, how it relates in a mutualistic way with the ecosystems it is part of, and how humans relate to both the living world and to the built environment and ultimately each other.

This paper demonstrates that by incorporating aspects of bio-inspired design into an understanding of regenerative architecture, significant environmental, social, and cultural benefits may accrue. In addressing our negative environmental impact, we may with such an approach, be able to create a more functional, liveable, loved, and beautiful habitat for ourselves.

\section{References}

[1] Cole, R.J., Changing context for environmental knowledge. Building Research and Information, 32(2), pp. 91-109, 2004.

[2] Rees, W., The built environment and the ecosphere: A global perspective. Building Research and Information, 27(4/5), pp. 206-220, 1999.

[3] Reed, B., Shifting from 'sustainability' to regeneration. Building Research and Information, 35(6), pp. 674-680, 2007.

[4] Walsh, R., Psychology and human survival: Psychological approaches to contemporary global threats. Psychology and Social Responsibility: Facing 
Global Challenges, ed. S. Staub and P. Green, New York University Press: New York, 1992.

[5] Hillman, J., City and Soul, ed. R.J. Leaver. Spring Publications: Putnam, Connecticut, 2006.

[6] Wilson, E.O., Biophilia. The Human Bond with Other Species, Harvard University Press: Cambridge, 1984.

[7] Storey, J.B. and M. Pedersen Zari. Factor X - well being as a key component of next generation green buildings. Proc. of the Rethinking Sustainable Construction'06 Conference, Sarasota, Florida, USA, 2006.

[8] Lohr, V., et al., Interior plants may improve worker productivity and reduce stress in a windowless environment. Journal of Environmental Horticulture, 14, 1996.

[9] Ulrich, R., View through a window may influence recovery from surgery. Science, 224, pp. 4647, 1984.

[10] Faber Taylor, A., et al., Views of nature and self discipline: evidence from inner city children. Journal of Environmental Psychology, 22, pp. 49-63, 2002.

[11] Tennessen, C.M. and B. Cimprich, Views to nature: effects on attention. Journal of Environmental Psychology, 15, pp. 77-85, 1995.

[12] Academy of Neuroscience for Architecture, Merging two disciplines: Architecture and neuroscience, 2003. Online. http://www.anfarch.org/

[13] Herman Miller Inc, Evolutionary psychology and workplace design, doing what comes naturally, report for COI, Calgary, 2004.

[14] Kellert, S.R., Building for Life, Island Press: Washington DC, 2005.

[15] Salingaros, N.A. and K.G. Masden. Neuroscience, the natural environment, and building design. Proc. of the Bringing Buildings to Life Conference, Yale University, 2006.

[16] Joye, Y., Fractal architecture could be good for you. Nexus Network Journal, 9(2), pp. 311, 2007.

[17] Taylor, R.P., Reduction of physiological stress using fractal art and architecture. Leonardo, 39(3), pp. 245-251, 2006.

[18] Ball, P., Life's lessons in design. Nature, 409, pp. 413-416, 2001.

[19] Pedersen Zari, M. and J.B. Storey. An ecosystem based biomimetic theory for a regenerative built environment. Proc. of the Lisbon Sustainable Building Conference 07. Lisbon, Portugal, 2007.

[20] Parker, A.R. and C.R. Lawrence, Water capture by a desert beetle. Nature, 414(6859), pp. 33, 2001.

[21] Reap, J., et al. Holism, biomimicry and sustainable engineering. Proc. of the ASME International Mechanical Engineering Conference and Exposition, Orlando, Florida, USA, 2005.

[22] Kibert, C.J., et al., Construction Ecology, Spon Press: New York, 2002.

[23] Benyus, J., Biomimicry - Innovation Inspired by Nature, Harper Collins Publishers: New York, 1997.

[24] Graham, P., Building Ecology - First Principles for a Sustainable Built Environment, Blackwell Publishing: Oxford, 2003. 
[25] Van der Ryn, S. and R. Pena, Ecologic analogues and architecture. Construction Ecology, ed. C.J. Kibert, J. Sendzimir, and G.B. Guy, Spon Press: London, pp. 231-247, 2002.

[26] McHarg, I., Design with Nature. 25th Anniversary ed., John Wiley and Sons Inc: New York, 1992.

[27] Bejan, A., Advanced Engineering Thermodynamics, Section 13.9: Science and civilization as constructal flow systems. 3rd ed. 2006, New York: Wiley.

[28] Bejan, A., Shape and Structure from Engineering to Nature. 2000, Cambridge: Cambridge University Press

[29] Kellert, S.R. and E.O. Wilson, The Biophilia Hypothesis, Island Press: Washington D.C., 1993.

[30] Gullone, E., The biophilia hypothesis and life in the 21st century: increasing mental health or increasing pathology? Journal of Happiness Studies, 1, pp. 293-321, 2000.

[31] Heerwagen, J., et al. Energy effectiveness and the ecology of work: Links to productivity and well-being. Proc. of the ACEEE Summer Study on Energy Efficiency in Buildings Conference, American Council for an Energy Efficient Economy: Washington, DC, 1998.

[32] Schweitzer, M., et al., Healing spaces: Elements of environmental design that make an impact on health. Journal of Alternative and Complementary Medicine, 10(Sup. 1), pp. 71-83, 2004.

[33] Vogel, S., Cat's Paws and Catapults, Norton and Company: New York, 1998.

[34] Vincent, J.F.V., et al. Biomimetics - its practice and theory. Journal of the Royal Society Interface, 3(9), pp. 471-482, 2006.

[35] Joye, Y., An interdisciplinary argument for natural morphologies in architectural design. Environment and Planning B: Planning and Design, 33(2), pp. 239-252, 2006.

[36] Fowles, R.A. Meeting human and ecological rights in creating the sustainable built environment. Proc. of the Conference on Environmental Justice and Global Citizenship. Copenhagen, Denmark, 2003.

[37] Storey, J.B. and M. Pedersen Zari. Factor X - Well Being as a Key Component of Next Generation Green Buildings. In Rethinking Sustainable Construction'06 Conference. 2006. Sarasota, Florida, USA 